\title{
Chronic bronchitis among French adults: high prevalence and underdiagnosis
}

\author{
G.J. Huchon*, A. Vergnenègre ${ }^{\#}$, F. Neukirch ${ }^{\Uparrow}$, G. Brami ${ }^{\S}$, N. Roche*, P-M. Preux ${ }^{f}$
}

Chronic bronchitis among French adults: high prevalence and underdiagnosis. G.J. Huchon, A. Vergnenègre, F. Neukirch, G. Brami, N. Roche, P-M. Preux. (C)ERS Journals Ltd 2002.

ABSTRACT: The aims of this survey were to determine the prevalence of symptoms indicative of chronic bronchitis $(\mathrm{CB})$ in the French adult population, to identify the role of risk factors for $\mathrm{CB}$, and to assess rates of $\mathrm{CB}$ diagnosis and pulmonary function testing (PFT) in the presence of CB.

A representative sample of 14,076 individuals aged $\geqslant 25$ yrs completed a selfadministered questionnaire on symptoms, comorbidities, smoking history, sociodemographical data, and diagnosis and care by physicians.

The prevalence of $\mathrm{CB}$ was $4.1 \%$ and the prevalence of chronic cough and/or expectoration was $11.7 \%$. In individuals with comorbidity, these figures were $10.4 \%$ and $\mathbf{2 4 . 4 \%}$, respectively. Smoking was associated with an increased frequency of $\mathrm{CB}$. In subjects with CB, $\mathbf{4 4 . 6 \%}$ had PFT (spirometry or peak expiratory flow measurement), $\mathbf{2 4} \%$ were diagnosed as having $\mathrm{CB}$, and $\mathbf{7 . 2 \%}$ received care. Rates of diagnosis, PFT, and follow-up were lower in young individuals and in those without comorbidity. PFT and follow-up were less common in current smokers.

Prevalence of chronic bronchitis in French adults is high and similar in magnitude to that of other industrialised countries. Comorbidities and tobacco smoking increase the frequency of chronic bronchitis symptoms. Chronic bronchitis is too infrequently diagnosed, investigated and cared for.

Eur Respir J 2002; 20: 806-812.
*University de Paris Pierre et Marie Curie, Service de Pneumologie et Réanimation, Hôtel-Dieu de Paris, Paris, ${ }^{\#}$ University de Limoges, Service de Pneumologie et Service de l'information médicale et de l'évaluation, Hôpital du Cluzeau, Limoges, "Laboratoire INSERM U408, Faculté de Médecine Xavier Bichat, Paris, ${ }^{\text {GlaxoSmith- }}$ Kline, Marly-Le-Roi, and ${ }^{f}$ University de Limoges, Unité de Biostatistique, Service de l'information médicale et de l'évaluation, Hôpital du Cluzeau, Limoges, France.

Correspondence: G.J. Huchon, Service de Pneumologie et Réanimation, HôtelDieu de Paris, 1 Parvis Notre Dame, F-75181 Paris 04, France.

Fax: 33142348448

E-mail: gerard.huchon@htd.ap-hopparis.fr

Keywords: Chronic obstructive pulmonary disease, comorbidity, lung function, smoking, survey

Received: January 32002

Accepted after revision: May 292002

This study was supported by grants from GlaxoSmithKline and Association pour 1'Etude de la Respiration et de $1^{\prime}$ Environnement.
In the 1950s and 1960s, chronic bronchitis (CB) was defined as chronic excessive mucous secretion in the bronchial tree, with chronic meaning occurring on most days for $\geqslant 3$ months in the year during $\geqslant 2$ consecutive years. This clinical definition included cough and expectoration, cough and swallowed expectoration, and expectoration with denied cough, as long as the symptoms were not attributable to other known lung diseases [1]. Later, several studies showed that $\mathrm{CB}$ itself did not cause chronic airflow obstruction. Moreover, both $\mathrm{CB}$ and chronic airflow obstruction were relatively independent responses to cigarette smoke and were associated with each other only because of the common noxious effects of smoking [2, 3]. In individuals with $\mathrm{CB}$, recurrent episodes of acute lower respiratory illnesses are responsible for time off work. In addition, recent analysis of data from the Lung Health Study suggests that, in persistent smokers, an increasing number of such episodes are associated with accelerated decline in lung function [4].

The expert report on the global strategy for the diagnosis, management, and prevention of chronic obstructive pulmonary disease (COPD) states that persons with chronic cough (CC) and sputum production are at risk of COPD, although not all develop airflow obstruction. Therefore, these subjects should have their lung function measured to detect those in whom COPD is present and offer them early intervention to alter the course and outcome of the disease [5]. Although $\sim 25 \%$ of the French adult population are smokers and $\geqslant 10,000$ die of COPD each year, at present there are no reliable data on the prevalence of $\mathrm{CB}$ in France. In addition, it may be suspected that, as in other countries [6], diagnosis of either CB or COPD is infrequently made and that lung function is seldom evaluated in patients with CB. Thus, a survey of the French adult population was designed to 
determine the prevalence of symptoms indicative of $\mathrm{CB}$, to identify the respective roles of some known risk factors for $\mathrm{CB}$, and to assess rates of $\mathrm{CB}$ diagnosis and lung function evaluation in patients with $\mathrm{CB}$.

\section{Materials and methods}

\section{Design of the survey}

The survey was performed by a professional poll institute (Taylor Nelson SOFRES Healthcare) on a representative panel of the French population aged $\geqslant 25$ yrs living within France, where there are 20 million households with 51 million inhabitants, including 41 million individuals $\geqslant 25$ yrs. The basis of sampling was a small-scale model that incorporated one out of 1,000 of the above-defined population. Thus, the sampling was made from a panel of 20,000 households (including 53,000 individuals) selected according to standard sociodemographical and geographical criteria. The five sampling criteria were the geographical area of residence, the type of habitat, the age of the index person, the profession and socioeconomic status, and the number of persons living in the household. There was no incentive to a medical examination in this survey.

\section{Questionnaire}

The self questionnaire was sent by mail in one single wave. Data obtained from each individual included some usual anthropometrical description, information on clinical symptoms, associated chronic diseases and presumptive diagnosis, and assessment of lung function. The self-administered questionnaire was derived from several validated and standardised questionnaires with three additional questions. The European Coal and Steel Community (ECSC) questionnaire [7], in its French translation, was used to evaluate smoking history and respiratory symptoms (frequency of cough, expectoration, dyspnoea, and wheezing). The World Health Organization questionnaire on occupational diseases [8] evaluated the prior existence of pleurisy, bronchiectasis, tuberculosis, heart failure, and/or chronic respiratory failure. The following three questions were added to these validated questionnaires to obtain information about pulmonary function testing, diagnosis of $\mathrm{CB}$ and management of $\mathrm{CB}$ by a physician. 1) "Did a doctor ever ask you to blow into a device to measure your breathing?" 2) "Did a doctor ever tell you that you had chronic bronchitis?" 3) "Are you currently followed by a doctor for chronic bronchitis?"

\section{Symptoms of chronic bronchitis}

Each subject was assigned to one of four groups: no cough and no expectoration, $\mathrm{CC}$, chronic expectoration (CE), CB. These groups were mutually exclusive. Individuals were considered as having cough if they answered positively to at least one of the following three questions: 1) "Do you usually cough during the day?" 2) "Do you usually cough during the night?" 3) "Do you usually cough when you get up?" The presence of expectoration was determined from the answer to the question "do you usually cough up phlegm during the day or during the night?" Cough and expectoration were considered chronic when occurring $\geqslant 3$ months a year for $\geqslant 2$ consecutive years. Individuals were considered as having $\mathrm{CB}$ if they answered yes to the question "have you had periods of cough and phlegm lasting 3 months or more each year during the last 2 years?", or if they answered yes to questions on both CC and CE. All patients of the $\mathrm{CB}$ group were then excluded from the $\mathrm{CC}$ and $\mathrm{CE}$ groups.

\section{Comorbidities}

A history of or the presence of pleurisy, pulmonary tuberculosis, bronchiectasis, heart failure, or asthma have been considered as comorbidities [8]. Patients were classified as asthmatic if they fulfilled one of the two following conditions. 1) They declared having asthma as confirmed by a physician. 2) They declared having asthma without confirmation by a physician and reported the occurrence of at least one of the following symptoms at least once during the previous year: "paroxysmal dyspnoea induced by an intense exercise", "awakening due to acute dyspnoea", "breathlessness with wheezing".

\section{Smoking}

Subjects were considered nonsmokers if they had smoked $<50$ cigarettes during their entire life, and as exsmokers if they stopped smoking $>1$ yr ago. The responses allowed the differentiation of three categories: nonsmokers, exsmokers and current smokers. Each subject's daily consumption (cigarettes per day) and cumulative consumption (pack-yrs) were then established and allowed the definition of two categorical variables $(\leqslant 1$, between 2 and $20, \geqslant 21$ cigarettes $\cdot$ day $^{-1}$; and $0,1-14,15-24$ and $\geqslant 25$ pack-yrs).

\section{Statistical analysis}

Considering the expected prevalence of $\mathrm{CB}(\sim 5 \%)$, an allowed risk of error of $0.5 \%$ of this percentage, and a possible analysis on two strata, 12,942 individuals had to be recruited for the survey. With an expected answering rate $\sim 85-90 \%$, the size of the necessary sample ranged between $13,700-14,700$ individuals.

Results are expressed as percentages with 95\% confidence intervals (CIs) or mean \pm SD. Prevalence frequencies are expressed as crude rate. Percentages were compared by two-way and multiway frequency analysis, and means by analysis of variance and unpaired t-test [9]. Multivariate logistic regressions were performed with variables that reached a $p<0.25$ difference in the univariate analysis [10]. A difference was considered significant if $\mathrm{p}<0.01$. 
Table 1.-Description and comparison of responders and nonresponders

Responders Nonresponders p-value

\begin{tabular}{|c|c|c|c|}
\hline \multicolumn{4}{|l|}{ Sex } \\
\hline Sex ratio M:F & 0.85 & 1.05 & 0.01 \\
\hline \multicolumn{4}{|l|}{ Age } \\
\hline $25-39$ yrs & $4634(32.9)$ & $1405(51.6)$ & 0.01 \\
\hline $40-59$ yrs & 4305 (30.6) & $822(30.2)$ & \\
\hline$>60 \mathrm{yrs}$ & $5137(36.5)$ & 497 (18.2) & \\
\hline Mean age yrs & 51.1 & 43.3 & 0.01 \\
\hline \multicolumn{4}{|l|}{$\begin{array}{l}\text { Socioeconomic } \\
\text { status }\end{array}$} \\
\hline Manual workers & $4285(30.4)$ & $1061(38.95)$ & 0.01 \\
\hline Managers & $3446(24.5)$ & $820(30.1)$ & 0.01 \\
\hline $\begin{array}{l}\text { Nonworking } \\
\text { population }^{+}\end{array}$ & $6345(45.1)$ & $843(30.95)$ & 0.01 \\
\hline \multicolumn{4}{|l|}{ Habitat } \\
\hline Rural & $3346(23.8)$ & $667(24.5)$ & NS \\
\hline $\begin{array}{l}\text { Town }<100000 \\
\text { inhabitants }\end{array}$ & $4535(32.2)$ & 808 (29.6) & NS \\
\hline $\begin{array}{l}\text { Town }>100000 \\
\text { inhabitants }\end{array}$ & $6195(44.0)$ & $1249(45.8)$ & NS \\
\hline \multicolumn{4}{|l|}{ Area } \\
\hline Paris area & $4993(35.5)$ & $1002(36.8)$ & NS \\
\hline North \& east & $2284(16.2)$ & $393(14.4)$ & NS \\
\hline West \& south-west & $3435(24.4)$ & $671(24.6)$ & NS \\
\hline $\begin{array}{l}\text { South-east \& Medi- } \\
\text { terranean area }\end{array}$ & $3364(23.9)$ & $658(24.2)$ & NS \\
\hline
\end{tabular}

Data are presented as $\mathrm{n}(\%)$ unless otherwise stated. $\mathrm{M}$ : male; F: female; NS: nonsignificant. ${ }^{\#}$ : farmers, employees, workers, etc.; : company managers, managerial staff, professional people, middlemen, shopkeepers, foremen, craftsmen etc.; ${ }^{+}$: retired, others.

\section{Results}

Sociodemographical characteristics of the 16,800 people to whom questionnaires were sent did not differ from those of the French population of $\geqslant 25$ yrs. The response rate was $83.5 \%$. Sociodemographical and socioprofessional data on responders $(n=14,076)$ and nonresponders $(n=2,724)$ are compared in table 1 .

Smoking habits varied according to age and sex (data not shown). Overall, $48.6 \%$ of responders $(34 \%$ of males and $61 \%$ of females) never smoked, $29.7 \%$ (40.3\% of males and $20.7 \%$ of females) were exsmokers, and $21.7 \%(25.7 \%$ of males and $18.4 \%$ of females) were current smokers. The proportion of current smokers decreased with age in both males and females. In males, this was linked to the agerelated increase in the number of subjects who stopped smoking, as indicated by the increased proportion of exsmokers and the unchanged proportion of never-smokers. In females, it was related to an increasing frequency of smoking in young subjects, as indicated by a decrease in the proportion of exsmokers and an increase in the proportion of never-smokers.

Comorbidities were reported by $16.7 \%$ of the individuals, including asthma $(8.7 \%)$, a history of tuberculosis $(2.4 \%)$, and heart failure $(4.1 \%)$. As shown in table 2, smoking patterns strongly influenced respiratory symptoms, both in the presence or absence of comorbidity.

Figure 1 shows the prevalence of $\mathrm{CB}$ to be $4.1 \%$ (95\% CI 3.8-4.5), CE 2.8\% (2.5-3.1), and CC 4.8\% (4.5-5.2) according to smoking status and the presence or absence of comorbidity.

Socioeconomic status, age and sex did not influence the prevalence of $\mathrm{CC}, \mathrm{CE}$ and $\mathrm{CB}$ (data not shown, $\mathrm{p}>0.25$ for each variable) and were not included in the multivariate analysis. Conversely, tobacco smoking and comorbidities were independently associated with CB symptoms (table 3 ).

Table 4 indicates the rates of pulmonary function

Table 2. - Smoking habits in subjects with chronic bronchitis (CB), chronic cough (CC), chronic expectoration (CE) or no symptoms, according to presence or absence of comorbid illnesses

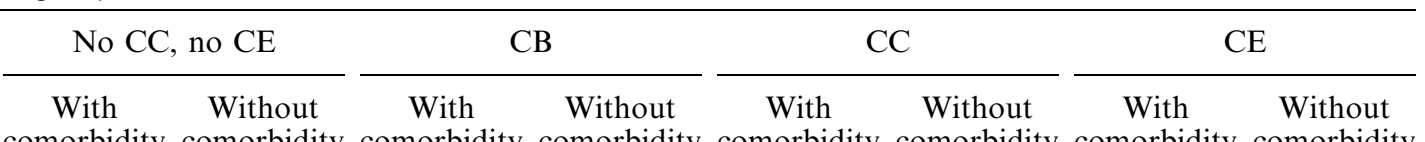

comorbidity comorbidity comorbidity comorbidity comorbidity comorbidity comorbidity comorbidity

\begin{tabular}{|c|c|c|c|c|c|c|c|c|}
\hline Subjects $n$ & 1772 & 11700 & 245 & 336 & 207 & 468 & 121 & 269 \\
\hline Current smokers & 14.9 & 20.2 & 28.2 & 57.4 & 26.1 & 50.0 & 19.8 & 27.1 \\
\hline 1-14 pack-yrs & 58.3 & 61.0 & 30.9 & 43.1 & 41.5 & 37.3 & 61.9 & 66.7 \\
\hline $15-24$ pack-yrs & 23.3 & 20.7 & 23.7 & 22.5 & 24.4 & 23.7 & 14.3 & 15.0 \\
\hline$\geqslant 25$ pack-yrs & 18.5 & 18.3 & 45.5 & 34.4 & 34.1 & 39.0 & 23.8 & 18.3 \\
\hline$<1 \mathrm{cig} \cdot \mathrm{day}^{-1}$ & 2.3 & 4.4 & 0 & 1.5 & 3.7 & 1.7 & 0 & 1.4 \\
\hline $2-20 \mathrm{cig} \cdot \mathrm{day}^{-1}$ & 68.6 & 67.7 & 46.4 & 42.5 & 51.9 & 35.5 & 62.5 & 61.6 \\
\hline$\geqslant 20 \mathrm{cig} \cdot \mathrm{day}^{-1}$ & 29.2 & 28.1 & 53.6 & 56.0 & 44.5 & 62.8 & 37.5 & 37.0 \\
\hline Duration yrs & $24.1 \pm 15.3$ & $21.9 \pm 12.9$ & $29.3 \pm 16.8$ & $24.3 \pm 13.7$ & $25.1 \pm 13.3$ & $24.3 \pm 12.9$ & $25.0 \pm 16.6$ & $19.9 \pm 12.4$ \\
\hline Exsmokers & 34.0 & 29.6 & 31.4 & 19.4 & 30.9 & 18.4 & 41.3 & 32.3 \\
\hline $1-14$ pack-yrs & 43.4 & 58.8 & 29.0 & 35.6 & 47.3 & 54.2 & 35.6 & 53.2 \\
\hline $15-24$ pack-yrs & 19.9 & 18.0 & 23.2 & 18.7 & 0.1 & 15.3 & 24.4 & 21.5 \\
\hline$\geqslant 25$ pack-yrs & 60.4 & 23.2 & 47.8 & 45.8 & 43.5 & 30.6 & 40.0 & 25.3 \\
\hline$<1 \mathrm{cig} \cdot \mathrm{day}^{-1}$ & 3.8 & 5.0 & 2.6 & 4.6 & 6.3 & 4.7 & 0.0 & 2.3 \\
\hline $2-20 \mathrm{cig} \cdot \mathrm{day}^{-1}$ & 55.2 & 56.9 & 42.9 & 46.2 & 45.3 & 53.5 & 60.0 & 60.9 \\
\hline$\geqslant 20 \mathrm{cig} \cdot \mathrm{day}^{-1}$ & 41.0 & 38.1 & 54.5 & 49.2 & 48.4 & 41.9 & 40.0 & 36.8 \\
\hline Duration yrs & $23.4 \pm 14.1$ & $18.0 \pm 12.0$ & $25.0 \pm 14.3$ & $26.1 \pm 13.4$ & $23.2 \pm 15.4$ & $19.8 \pm 12.7$ & $26.1 \pm 12.7$ & $20.3 \pm 12.2$ \\
\hline Nonsmokers & 51.1 & 50.3 & 40.4 & 23.2 & 43.0 & 31.6 & 38.8 & 40.5 \\
\hline
\end{tabular}

Data are expressed as $\%$ of the population unless otherwise stated. 


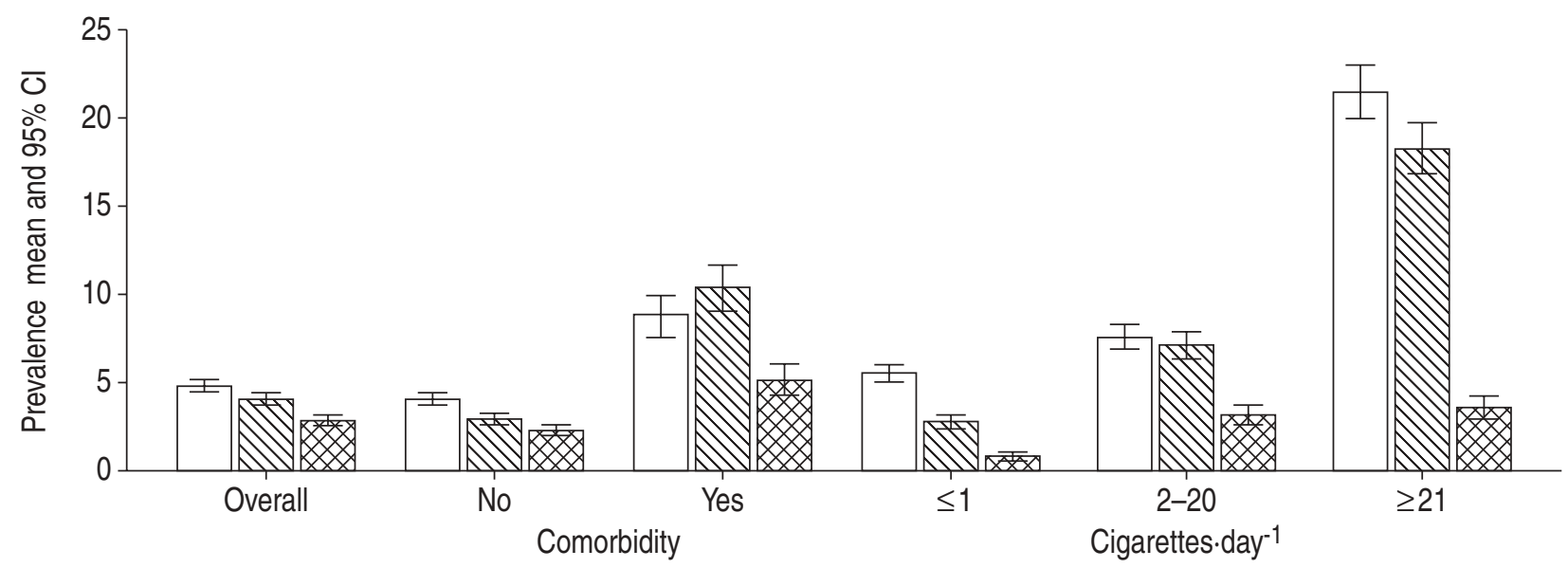

Fig. 1. - Prevalence of chronic cough $(\square)$, chronic bronchitis $(\mathbb{\mathbb { Q }})$ and chronic expectoration $(\mathbf{Q})$ according to the presence or absence of comorbidities and smoking habits. CI: confidence interval.

evaluation by peak expiratory flow rate measurement or spirometry, diagnosis of $\mathrm{CB}$, and follow-up for $\mathrm{CB}$. In subjects with $\mathrm{CB}$, pulmonary function evaluation, diagnosis of $\mathrm{CB}$, and follow-up for $\mathrm{CB}$ were more likely in older individuals $(\mathrm{p}<0.001)$ and in those with a comorbidity $(\mathrm{p}<0.001)$. Diagnosis of $\mathrm{CB}$ did not differ among smokers, exsmokers and nonsmokers, but in smokers, pulmonary function evaluation (49.8\%, $\mathrm{p}=0.015)$ and follow-up for $\mathrm{CB}(13.8 \%$, $\mathrm{p}=0.002)$ were less frequent than in nonsmokers $(62.2$ and $27.3 \%$ ) and exsmokers (61.3 and $22.7 \%$ ).

\section{Discussion}

In a representative sample of the adult French population aged $\geqslant 25$ yrs (40.5 million people), this study found overall prevalences of $4.1 \%$ for $\mathrm{CB}$ (1.7 million), $4.8 \%$ for $\mathrm{CC}$ and $2.8 \%$ for CE. These figures were $2.9 \%, 4 \%$ and $2.3 \%$, respectively, in individuals without comorbidity. Comorbidities and smoking were both associated with an increased frequency of $\mathrm{CB}$. In subjects who declared symptoms of $\mathrm{CB}$ but no comorbidity, a diagnosis of $\mathrm{CB}$ was made

Table 3. - Risk factors for chronic cough, chronic expectoration and chronic bronchitis ${ }^{\#}$

\begin{tabular}{llccr}
\hline & Reference & Odds ratio & $95 \%$ Confidence interval & p-value \\
\hline Chronic cough & & & & \\
$\quad$ Current smokers & Nonsmokers & 2.79 & $2.30-3.39$ & $<0.0001$ \\
$\quad$ Comorbidity & No comorb & 2.94 & $2.47-3.50$ & $<0.0001$ \\
$\quad \begin{array}{l}\text { Pack-yrs } \\
\text { Chronic expectoration }\end{array}$ & 1 & 1.01 & $1.01-1.02$ & $<0.0001$ \\
$\quad$ Current smokers & Nonsmokers & 1.64 & $1.24-2.16$ & $<0.0001$ \\
$\quad$ Comorbidity & No comorb & 2.74 & $2.19-3.42$ & $<0.0001$ \\
Chronic bronchitis & Nonsmokers & 3.41 & $2.75-4.22$ & $<0.0001$ \\
$\quad$ Current smokers & No comorb & 4.90 & $4.10-5.86$ & $<0.0001$ \\
Comorbidity & 1 & 1.02 & $1.01-1.02$ & $<0.0001$ \\
Pack-yrs & & & \\
\hline
\end{tabular}

\#: calculated by multivariate logistic regression analysis and adjusted for age and sex.

Table 4. - Individuals with chronic bronchitis (CB), chronic cough (CC) and chronic expectoration (CE) who had pulmonary function evaluation, a diagnosis of $C B$ made, and/or were followed-up for $C B$

\begin{tabular}{|c|c|c|c|c|c|c|}
\hline & \multicolumn{2}{|c|}{$\mathrm{CB}$} & \multicolumn{2}{|c|}{$\mathrm{CC}$} & \multicolumn{2}{|c|}{$\mathrm{CE}$} \\
\hline & $\begin{array}{l}\text { With } \\
\text { comorbidity }\end{array}$ & $\begin{array}{l}\text { Without } \\
\text { comorbidity }\end{array}$ & $\begin{array}{l}\text { With } \\
\text { comorbidity }\end{array}$ & $\begin{array}{l}\text { Without } \\
\text { comorbidity }\end{array}$ & $\begin{array}{l}\text { With } \\
\text { comorbidity }\end{array}$ & $\begin{array}{c}\text { Without } \\
\text { comorbidity }\end{array}$ \\
\hline $\begin{array}{l}\text { Pulmonary function } \\
\text { evaluation }\end{array}$ & 72.2 & 44.6 & 72.5 & 41.9 & 70.3 & 43.3 \\
\hline Diagnosis of $\mathrm{CB}$ & 52.3 & 24.0 & 38.8 & 14.2 & 39.8 & 12.3 \\
\hline Follow-up for CB & 37.6 & 7.2 & 23.7 & 3.7 & 21.0 & 3.3 \\
\hline
\end{tabular}

Data are percentages. 
in only $24 \%$; pulmonary function was evaluated by spirometry or peak flow meter in $45 \%$; and $7 \%$ were being followed for CB.

Some potential sources of bias may have influenced the results of this survey. The response rate $(83.5 \%)$ is comparable to that of similar surveys in which the same differences in sex, age and socioeconomic status have been observed between responders and nonresponders [11]. Answering rates generally tend to be higher in females, older subjects and nonworking individuals. Another source of bias is the declarative nature of the study, without any verification by a physician. The corresponding frequency estimates are generally considered to be underestimates for most chronic lung diseases, including CB [11]. However, the reliability of the data concerning $\mathrm{CB}$ in this study is indirectly suggested by the apparently accurate rate of reported asthma $(8.7 \%)$, which agrees with data from several cross-sectional studies [12, 13]. Overall, current smoking rate was slightly lower than expected in the present survey: $21.7 \%$ versus $27.0 \%$ in a large population survey of French males and females aged $\geqslant 15$ yrs [14]. As in most surveys, the rate of smoking is lower in females than in males and decreases with age [15]. Thus, differences in methodology and, especially, in the sex and age of subjects may contribute to discrepancies in smoking rates among surveys.

There were no previous data on the prevalence of $\mathrm{CB}$ in the whole French adult population, which was estimated from studies of smokers at the end of the 1970 s to be $\sim 5 \%$ [16]. The present study found a prevalence of $4.1 \%$ for $\mathrm{CB}, 4.8 \%$ for $\mathrm{CC}$ and $2.8 \%$ for $\mathrm{CE}$ among all responders and $2.9 \%$ for $\mathrm{CB}, 4.0 \%$ for $\mathrm{CC}$ and $2.3 \%$ for $\mathrm{CE}$ in individuals without comorbidity. These figures may seem low when compared to previous estimations, which may in part be due to the declarative nature of this survey. Although there is no way of determining the magnitude of the corresponding underestimation, it can be inferred from asthma reporting rate that it is not high. In addition, separation of $\mathrm{CC}, \mathrm{CE}$ and $\mathrm{CB}$ has probably underestimated the number of declared $\mathrm{CB}$ by excluding both patients with $\mathrm{CC}$ who swallow expectorations and those with $\mathrm{CE}$ who deny cough [1]. The definition of $\mathrm{CB}$ varies in available guidelines: for example, the American Thoracic Society guidelines mention chronic productive cough (i.e. both cough and expectoration) while European Respiratory Society guidelines require only chronic expectoration as a sign of chronic mucous hypersecretion $[17,18]$. The purpose of excluding chronic expectoration without chronic cough from the definition of $\mathrm{CB}$ in this survey was to exclude patients who do not differentiate, e.g. posterior nasal discharge and chronic expectoration, which may lead to false-positive declarations and thereby overestimation of $\mathrm{CB}$ prevalence. If chronic expectoration without declared chronic cough had been included in the definition of $\mathrm{CB}$, the frequency of $\mathrm{CB}$ would have been $6.9 \%$ instead of $4.1 \%$.

It is impossible to determine the proportion of patients with comorbidities in whom $\mathrm{CB}, \mathrm{CC}$ or $\mathrm{CE}$ are not the consequence of the comorbidity, but are related to smoking or other risk factors. Therefore, prevalence of $\mathrm{CB}$ was presented separately for subjects with and without comorbid conditions. Clearly, the prevalence of asthma (which was the most frequent comorbid illness) cannot be considered entirely reliable because of the declarative nature of the survey. However, the diagnostic criteria that were used are commonly employed in epidemiological surveys on this disease $[7,12,13]$ and reported symptoms without a diagnostic confirmation by a physician accounted for only $12 \%$ of patients identified as asthmatics according to the authors' algorithm. In addition, the frequency of asthma found in this study is close to that reported in studies dedicated to assessing the epidemiology of this disease.

There are only a few surveys assessing the prevalence of $\mathrm{CB}$ in the general population. The US National Centre for Health Statistics periodically collects data on respiratory disorders in its health interview surveys. The prevalence of $\mathrm{CB}$ reported in samples of the adult civilian noninstitutionalised population increased from $3.3 \%$ in 1970 to $5.3 \%$ in 1993 [11, 19], which is close to what was obtained in the current survey. However, other similar crosssectional epidemiological studies based on representative samples of the general population report higher figures, such as $9 \%$ in northern Sweden [20], 12.7\% in southern Brazil [21], and even $13.5 \%$ in a rural area of Kayseri, Central Anatolia, Turkey [22]. Such discrepancies may be real or they may be explained by differences in survey methodology.

Risk factors for CB have already been identified by various studies in the 1970s [23]: cigarette smoking is by far the most important, being more frequent in males than in females and increasing as the number of years of smoking cumulates; a high prevalence of $\mathrm{CB}$ is also associated with certain known occupational hazards. Accordingly, in the present survey, being a current smoker increased the risk of having CB. Moreover, the risk rose with increasing numbers of pack-yrs but not with age per se. Daily cigarette consumption was highest among patients with $\mathrm{CB}$. Neither occupation nor the place of living had detectable effects on the rate of $\mathrm{CB}$, despite studies that have shown that some occupations increase the prevalence of CB [24-31], and other studies that have demonstrated differences in $\mathrm{CB}$ prevalence among geographical areas $[32,33]$. The present survey found differences only in $\mathrm{CC}$ and $\mathrm{CE}$ among people living either in the east of France or in Ile-de France. The lack of effect of occupation is probably due to the general nature of the occupational classification that was used. A more precise assessment of occupational risk factors would have required a much longer questionnaire, which may have compromised the response rate and, thereby, the achievement of the primary goal, i.e. the determination of $\mathrm{CB}$ prevalence.

In individuals with $\mathrm{CB}$ without comorbidity, $44.6 \%$ had lung function tests (either peak expiratory flow rate measurement or spirometry), $24 \%$ were diagnosed as having $\mathrm{CB}$, and $7.2 \%$ were receiving care for it. These figures were $72.2 \%, 52.3 \%$ and $37.6 \%$, respectively, when there was comorbidity. These data suggest that symptoms indicative of $\mathrm{CB}$ receive poor attention from physicians, except when they occur in 
the context of a known illness, such as asthma or chronic heart disease. CB in young individuals and in persons without comorbidity was unlikely to be diagnosed, and these subjects were less likely to undergo pulmonary function evaluation and to receive care. In active smokers with $\mathrm{CB}$, pulmonary function evaluation and follow-up for $\mathrm{CB}$ occurred less frequently than in nonsmokers and exsmokers. These data are similar to results of other studies that have shown that diagnosis and care of $\mathrm{CB}$ are infrequent despite the potential hazards, i.e. chronic respiratory failure, lung carcinoma, related to that condition [5, 6, 34]. This lack of consideration of symptoms of $\mathrm{CB}$ by both physicians and patients, particularly in smokers and young individuals without comorbidity, is likely to delay medical intervention, which could ultimately lead to an increased disability and mortality. Thus, increasing efforts should be put into improving knowledge on CB and COPD, both in the general and medical populations. Because $\mathrm{CB}$ is the earliest manifestation of bronchial susceptibility to cigarette smoke and is a precursor of COPD, symptoms should be monitored intensively to allow early detection and prevention of COPD.

In conclusion, this survey shows that in France, symptoms indicative of chronic bronchitis are frequent, particularly in smokers and patients with comorbidities. Both the diagnosis and the level of care of these patients are markedly low, particularly when considering the risk of occurrence of chronic obstructive pulmonary disease in this population.

Acknowledgements. The authors would like to thank E. Chailleux, C. Chidiac, M. Fournier, J.P. Grignet, E. Guignard, T. Lebrun, P. Léophonte, J.F. Lhuillier, J.F Muir, P. Petitpretz, P. Serrier, J. Vergeret, P. Weinbreck, and P. Zuck for their advice in the design of the survey.

\section{References}

1. Fletcher CM, Gilson JG, Hugh-Jones P, Scadding JG. Terminology, definitions, and classification of chronic pulmonary emphysema and related conditions. A report of the conclusions of a Ciba guest symposium. Thorax 1959; 14: 286-299.

2. Kauffmann F, Drouet D, Lellouch J, Brille D. Twelve years spirometric changes among Paris area workers. Int J Epidemiol 1979; 8: 201-212.

3. Peto R, Speizer FE, Cochrane AL, et al. The relevance in adults of air-flow obstruction, but not of mucus hypersecretion, to mortality from chronic lung disease. Results from 20 years of prospective observation. $\mathrm{Am}$ Rev Respir Dis 1983; 128: 491-500.

4. Kanner RE, Anthonisen NR, Connett JE. Lower respiratory illnesses promote FEV1 decline in current smokers but not ex-smokers with mild chronic obstructive pulmonary disease: results from the lung health study. Am J Respir Crit Care Med 2001; 164: 358-364.

5. Pauwels RA, Buist AS, Calverley PM, Jenkins CR, Hurd SS. The GOLD Scientific Committee. Global strategy for the diagnosis, management, and prevention of chronic obstructive pulmonary disease. NHLBI/ WHO Global Initiative for Chronic Obstructive Lung Disease (GOLD) Workshop summary. Am J Respir Crit Care Med 2001; 163: 1256-1276.

6. Petty TL. Scope of the COPD problem in North America. Early studies of prevalence and NHANES III data: basis for early identification and intervention. Chest 2000; 117: 326S-331S.

7. Minette A. Questionnaire of the European Community for Coal and Steel (ECSC) on respiratory symptoms. 1987-updating of the 1962 and 1967 questionnaires for studying chronic bronchitis and emphysema. Eur Respir J 1989; 2: 165-177.

8. OMS: Le dépistage précoce des maladies professionnelles: questionnaire sur les symptômes respiratoires (version française du questionnaire du British Medical Research Council) 1 vol. OMS, Genève, 1989; pp. 280-283.

9. Zar JH. Biostatistical analysis. Englewood Cliffs, NJ, Prentice-Hall, 1974.

10. Hoswer DW, Lemeshow S. Applied logistic regression. New York, Wiley \& Sons, 1989; p. 307.

11. US Department of Health and Human Services. National Heart Lung and Blood Institute, Division of Lung Diseases. Report of a task force on epidemiology of lung diseases. DHHS Publication No. NIH 81-2019. Washington DC, Government Printing Office, 1980.

12. Com-Ruelle L, Crestin B, Dumesnil S. Asthma in France by degree of severity. CREDES 2000; 1290: 182.

13. Pearce N, Sunyer J, Cheng S, et al. Comparison of asthma prevalence in the ISAAC and the ECRHS. ISAAC Steering Committee and the European Community Respiratory Health Survey. International Study of Asthma and Allergies in Childhood. Eur Respir J 2000; 16: 420-426.

14. Aliaga C. Le tabac: vingt ans d'usage et de consommation. Insee Première n ${ }^{\circ} 08$. Paris, INSEE, 2001.

15. Sobradillo V, Miravitlles M, Jimenez CA, et al. Epidemiological study of chronic obstructive disease in Spain (IBERPOC): prevalence of chronic respiratory symptoms and airflow limitation. Arch Bronchopneumol 1999; 35: 159-166.

16. Huchon G, Fournier M, Lebas FX, et al. Recommandations pour la prise en charge des bronchopneumopathies chroniques obstructives. Rev Mal Respir 1997; 14: 2S3-2S91.

17. American Thoracic Society. Standards for the diagnosis and care of patients with chronic obstructive pulmonary disease. Am Rev Respir Dis 1995; 152: S77-S120.

18. Siafakas NM, Vermeire P, Pride NB, et al. Optimal assessment and management of chronic obstructive pulmonary disease (COPD). Eur Respir J 1995; 8: 1398-1420.

19. Collins JG. Prevalence of selected chronic conditions: United States, 1990-1992. Vital Health Stat 1997; 194: 1-89.

20. Lundback B, Stjernberg N, Nystrom L, Lundback K, Lindstrom M, Rosenhall L. An interview study to estimate prevalence of asthma and chronic bronchitis. The obstructive lung disease in northern Sweden study. Eur J Epidemiol 1993; 9: 123-133.

21. Menezes AM, Victora CG, Rigatto M. Prevalence and 
risk factors for chronic bronchitis in Pelotas, RS, Brazil: a population-based study. Thorax 1994; 49: 1217-1221.

22. Cetinkaya F, Gulmez I, Aydin T, Ozturk Y, Ozesmi M, Demir R. Prevalence of chronic bronchitis and associated risk factors in a rural area of Kayseri, Central Anatolia, Turkey. Monaldi Arch Chest Dis 2000; 55: 189-193.

23. Thurlbeck WM. Epidemiology of chronic airflow obstruction, chronic bronchitis, and emphysema. In: Thurlbeck WM, ed. Chronic airflow obstruction in lung disease. Philadelphia, WB Saunders, 1976; pp. 235-287

24. Bradshaw LM, Fishwick D, Slater T, Pearce N. Chronic bronchitis, work related respiratory symptoms, and pulmonary function in welders in New Zealand. Occup Environ Med 1998; 55: 150-154.

25. Niven RM, Fletcher AM, Pickering CA, et al. Chronic bronchitis in textile workers. Thorax 1997; 52: 22-27.

26. Melbostad E, Eduard W, Magnus P. Chronic bronchitis in farmers. Scand J Work Environ Health 1997; 23: 271-280.

27. Fishwick D, Bradshaw LM, D'Souza W, et al. Chronic bronchitis, shortness of breath, and airway obstruction by occupation in New Zealand. Am J Respir Crit Care Med 1997; 156: 1440-1446.
28. Vergnenegre A, D'arco X, Melloni B, et al. Work related distal airway obstruction in an agricultural population. Occup Environ Med 1995; 52: 581-586.

29. Gupta SK, Singh SK. A study on the prevalence of chronic bronchitis in workers exposed to smoke and irritant fumes in a railway workshop. Indian $J$ Chest Dis Allied Sci 1992; 34: 25-28.

30. Chen Y, Horne SL, McDuffie HH, Dosman JA. Combined effect of grain farming and smoking on lung function and the prevalence of chronic bronchitis. Int J Epidemiol 1991; 20: 416-423.

31. Jorgensen HS, Kolmodin-Hedman B, Stjernberg N. Follow-up study of pulmonary function and respiratory tract symptoms in workers in a Swedish iron ore mine. J Occup Med 1988; 30: 953-958.

32. Bjornsson E, Plaschke P, Norrman E, et al. Symptoms related to asthma and chronic bronchitis in three areas of Sweden. Eur Respir J 1994; 7: 2146-2153.

33. Dalphin JC, Debieuvre D, Pernet D, et al. Prevalence and risk factors for chronic bronchitis and farmer's lung in French dairy farmers. Br J Ind Med 1993; 50: 941-944.

34. Petty TL. Screening strategies for early detection of lung cancer: the time is now. JAMA 2000; 284: 1977-1980. 